\title{
The relief of bone pain in primary biliary cirrhosis with calcium infusions
}

\author{
A. B. AJDUKIEWICZ, J. E. AGNEW, P. D. BYERS, M. R. WILlS ${ }^{1}$, AND \\ SHEILA SHERLOCK
}

From the Departments of Medicine, Physics, and Chemical Pathology, Royal Free Hospital, London, and the Institute of Orthopaedics, London

SUMMARY Intravenous calcium infusions produced subjective relief of bone pain in 14 patients with primary biliary cirrhosis. The bone pain had developed despite long-term parenteral vitamin D therapy. The pain returned after two to three months, but a subsequent course of infusions again brought relief. Before treatment satisfactory iliac crest bone biopsies were obtained in 11 of the patients and were normal in seven; two patients had biopsies indicating osteomalacia and two osteoporosis. After treatment a repeat biopsy in one of the patients with osteomalacia showed marked reduction in osteoid. The infusion treatment produced no change in plasma calcium concentration, serum phosphate, or serum alkaline phosphatase. Absorption of oral calcium was also unchanged.

Metabolic bone diseases, both osteoporosis and osteomalacia, complicate hepato-biliary disorders (Atkinson, Nordin, and Sherlock, 1956; Lichtwitz, Cachin, Hioco, Tutin, and de Sèze, 1959). Osteoporosis is characterized by a diminished volume of bone and is the end result of many processes. Osteomalacia is a disease produced by a lack of cholecalciferol (vitamin $D_{3}$ ) and its biologically active metabolites, and is manifested in bone by reduced mineralization and excessive amounts of osteoid. Bone pain in patients with primary biliary cirrhosis may be due to osteomalacia, osteoporosis with or without fractures, and rarely to periosteal reactions.

Despite the administration of parenteral vitamin D some patients with primary biliary cirrhosis develop bone pain either in association with osteomalacia, fractures, and periosteal reactions or, rarely, in the absence of these findings. Pak, Zisman, Evens, Jowsey, Delea, and Bartter (1969) treated six patients with idiopathic osteoporosis and fractures using intravenous calcium infusions. They reported improvement both clinical and in calcium retention, bone formation was enhanced, bone resoprtion reduced, and gastrointestinal calcium absorption increased. In view of these

${ }^{1}$ Correspondence to Dr M. R. Wills, Department of Chemical Pathology, Royal Free Hospital, Gray's Inn Road, London WC1X 8LF

Received for publication 3 July 1974. findings the present study was undertaken to investigate the effect of intravenous calcium infusions in 14 patients with primary biliary cirrhosis who complained of bone pain, all of whom had received parenteral vitamin D. Plasma calcium and phosphate concentrations, plasma alkaline phosphate activity, and intestinal calcium absorption were measured and bone biopsies performed.

\section{Methods}

\section{CALCIUM INFUSION}

Each patient received a calcium infusion daily for 12 consecutive days. Each infusion consisted of calcium gluconate diluted in $5 \%$ dextrose to about $500 \mathrm{ml}$ and administered intravenously over four hours. The dose of calcium was $1.5 \mathrm{mg} / \mathrm{kg}$ body weight (low dose) or $15 \mathrm{mg} / \mathrm{kg}$ body weight (high dose).

In seven patients a pulse of $10 \mu \mathrm{Ci}{ }^{47} \mathrm{Ca}$ was added to the first infusate. The activity remaining in the drip bottle and tubing was checked. The fate of the pulse was followed by stool and urine collections, and in six patients by whole body counting.

\section{CALCIUM ABSORPTION}

Retention of ${ }^{47} \mathrm{Ca}$ was measured by a simple single crystal whole body counter which has been shown to provide a good index of ${ }^{47} \mathrm{Ca}$ absorption (Agnew, Kehayoglou, and Holdsworth, 1969). Ten $\mu \mathrm{Ci}$ 
${ }^{47} \mathrm{Ca}$ in $200 \mathrm{ml}$ of milk (calcium content approximately $240 \mathrm{mg}$ ) was given orally to the patients after overnight fasting. Patients remained fasting for a further three hours after taking the isotope. Urine was collected for two days to check renal excretion of ${ }^{47} \mathrm{Ca}$ in order to exclude any patient in whom excessive renal excretion would invalidate this method of measuring calcium absorption. The whole body counter result was expressed as the percentage retention of the isotope at seven days.

\section{BONE BIOPSY}

Decalcified and undecalcified sections and microradiographs were prepared from all sections (Drury and Wallington, 1967).

A qualitative examination was made of the architecture (gross anatomy), structure (collagen organization), periosteocytic mineral distribution, and osteoid mineralization (calcification front).

A quantitative assessment was made of bone area as a percentage of cancellous compartment, osteoid area as a percentage of cancellous compartment, osteoid as a percentage of bone surface, and resorption as a percentage of bone surface.

The interpretation of bone biopsies has been described in detail by Byers (1974). The quantitative analysis (point and linear sampling with a Zeiss integrating graticule) was used to determine if actual levels were exceeded, viz:

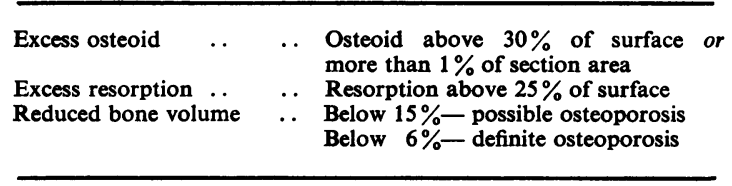

Excess osteoid was taken as indicating osteomalacia, excess resorption as indicating hyperparathyroidism, and reduced bone volume as indicating osteoporosis.

\section{BIOCHEMISTRY}

Calcium in plasma and urine was determined by atomic absorption spectrophotometry and other biochemical determinations were performed by routine laboratory methods.

\section{PATIENTS STUDIED}

The 14 patients were all suffering from primary biliary cirrhosis diagnosed according to recognized criteria (Sherlock and Scheuer, 1973; Sherlock, 1974). They were all female and the duration of illness was from two to 10 years (table I). None of the patients was suffering from portosystemic encephalopathy. Fluid retention was present in seven patients.

All the patients complained of backache and also had pain in the arms, legs, or ribs. Apart from case 7 , they had all received intramuscular vitamin $D_{2}, 100000$ iu every month for one to seven years. Fractures (table I) were present in seven patients. There was no evidence of thyroid or pituitaryadrenal axis dysfunction as assessed by estimation of serum $T_{3}$, serum thyroxine and circadian cortisol studies; nor was there any evidence of renal tubular dysfunction as evidenced by urine amino acid chromatography. Blood urea was normal in all patients.

The dietary intake of calcium and of protein was similar in the infused patients to that of patients of similar ages suffering from non-biliary chronic

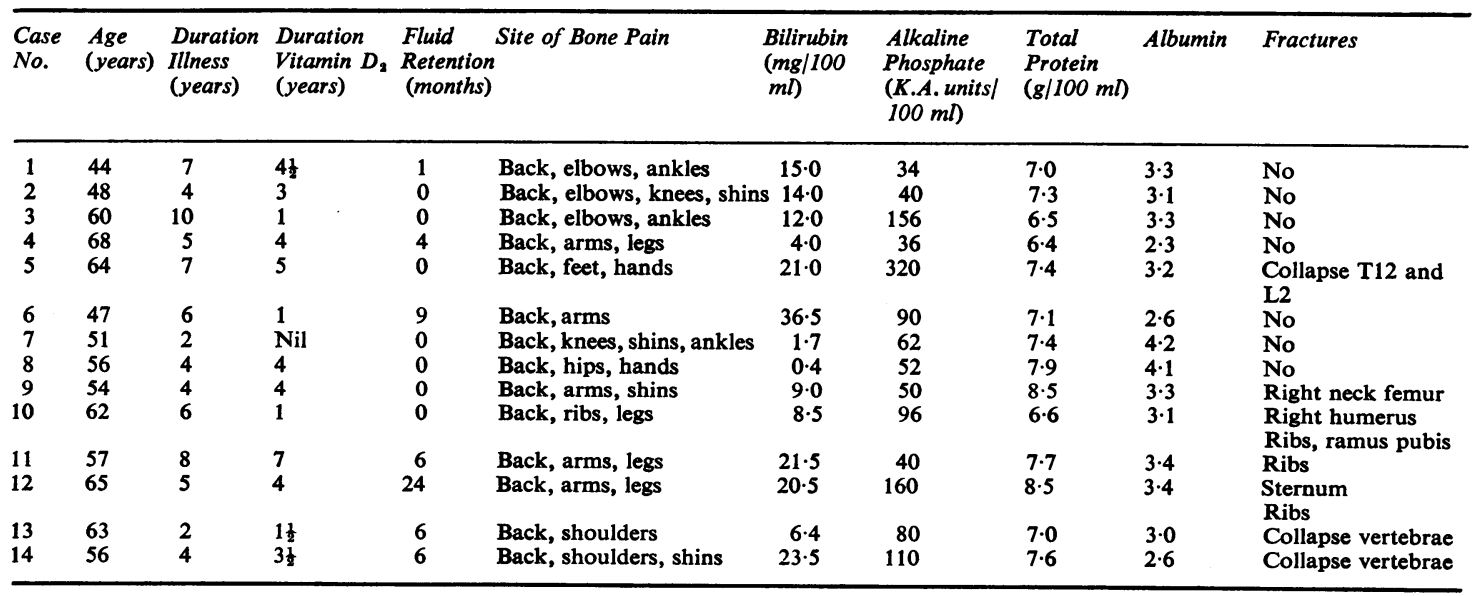

Table I Clinical and biochemical findings in the patients with primary biliary cirrhosis studied 


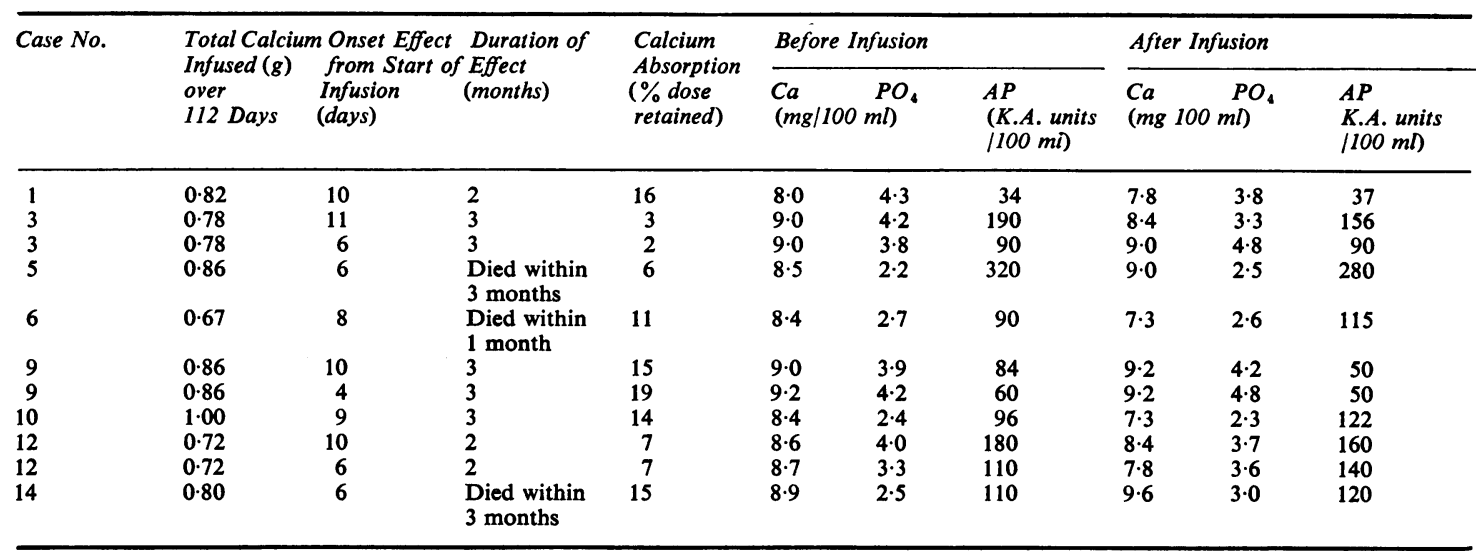

Table II Clinical and biochemical response to low-dose calcium infusion therapy

liver disease. Five patients were only taking about $40 \mathrm{~g}$ of protein.

\section{Results}

In no patient did any untoward symptom necessitate stopping treatment. Two patients (cases 2 and 7) complained of nausea, in case 2 accompanied by headache, towards the end of the last three days of high dose infusion treatment.

Blood urea concentrations were normal both before and after treatment. In none was there any change in plasma creatinine concentration nor was there any change in endogenous creatinine clearance.

Throughout the treatment the patients were never questioned about bone pains until they themselves referred to the subject. In fact all patients volunteered the information that the bone pain was diminishing. Pain, judged by the patient's reactions, was relieved in three to 12 days from the onset of infusions and the relief lasted for two to three months. The relief of bone pain was achieved more rapidly using the high dose infusions, but there was no difference in the duration of remission despite the variation in dose (tables II and III).

Six patients died within three months of having the calcium infusion, reflecting the advanced stage of the disease of the patients studied. Five patients had repeated infusions.

Plasma calcium concentrations had not altered significantly on the day following the infusion

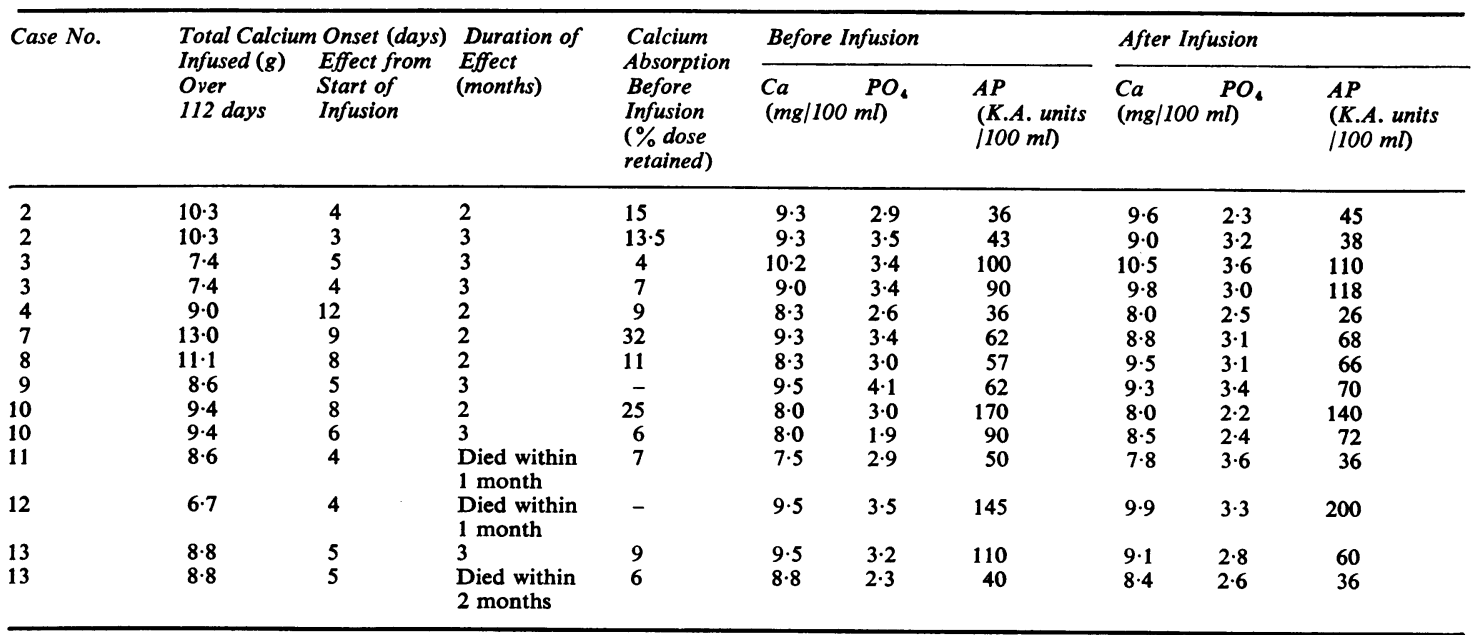

Table III Clinical and biochemical response to high-dose calcium infusion therapy 


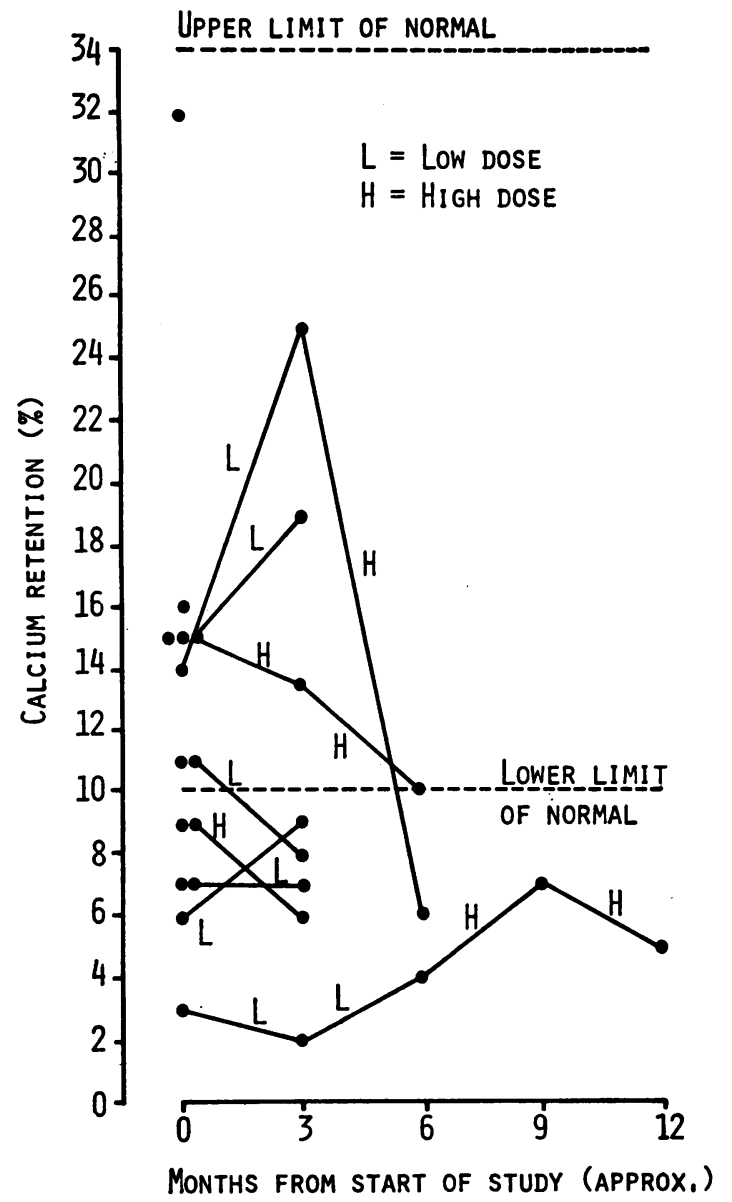

Fig Effect of calcium infusions (iv) on calcium retention treatment. In those on high dose infusion there was a mean rise of $0.12 \mathrm{mg} / 100 \mathrm{ml}$ and on low dose a mean fall of $0.25 \mathrm{mg} / 100 \mathrm{ml}$ (tables II and III).

\section{CALCIUM ABSORPTION}

Before treatment calcium absorption as measured by retention was subnormal in six patients (see fig). In patient 10 , with marked osteomalacia, retention rose from 14 to $25 \%$; the other patients showed little change.

\section{BONE BIOPSIES (TABLE IV)}

In seven patients (cases $1,3,4,7,8,13$, and 14) bone biopsies were essentially normal. One further patient (case 2) was also probably normal although the specimen was fragmented.

Two patients (cases 10 and 11) showed osteomalacia, in one of whom (case 11) bone volume was low. Patient 10 had very striking osteomalacia despite a year's vitamin D treatment. At necropsy one year later, the iliac crest was classified as only possible osteoporosis. In other bones studied at necropsy (skull, rib, vertebra, and femoral shaft) bone volume was not so obviously reduced and osteoid was within normal limits. The second patient (case 11) was less definitely osteomalacic in that surface coverage was just within normal limits and osteoid mineralization was not obviously altered-but the osteoid area was high.

Two patients (cases 9 and 12) showed osteoporosis. Case 12 had extremely low osteoid levels before and after treatment, together with active, normal, and possibly increasing, resorption. This makes the decrease in bone area from 10 to $5 \%$ appear a real one-indicating a progressive osteo-

\begin{tabular}{|c|c|c|c|c|c|}
\hline \multirow[t]{3}{*}{ Case } & & \multicolumn{4}{|l|}{ Iliac Crest } \\
\hline & & \multicolumn{2}{|l|}{ Osteoid } & \multirow{2}{*}{$\frac{\text { Resorption }}{\% \text { Surface }}$} & \multirow{2}{*}{$\frac{\text { Bone }}{\% \text { Area }}$} \\
\hline & & $\%$ Surface & $\%$ Area & & \\
\hline 1 & Pre & $<10$ & $<1$ & 5 & 20 \\
\hline \multirow[t]{2}{*}{3} & Pre & $<10$ & $<1$ & 10 & 15 \\
\hline & Post & $<10$ & $<1$ & 10 & 15 \\
\hline \multirow{5}{*}{$\begin{array}{l}4 \\
7 \\
8 \\
9\end{array}$} & Pre & $<10$ & $<1$ & 15 . & 20 \\
\hline & Pre & $<10$ & $<1$ & $>5$ & 15 \\
\hline & Pre & $<10$ & $<1$ & 12 & 15 \\
\hline & Pre & & Unsatisfactory & Biopsy & \\
\hline & Post & $\mathbf{0}$ & 0 & 2 & 5 \\
\hline \multirow[t]{2}{*}{10} & Pre & 99 & $>1(11 \%)$ & 1 & 25 \\
\hline & Post & $<10$ & $<1(0.6 \%)$ & 15 & 11 \\
\hline \multirow{3}{*}{$\begin{array}{l}11 \\
12\end{array}$} & Pre & 25 & $>1(2 \%)$ & 10 & 15 \\
\hline & Pre & $<10$ & $<1(0.1 \%)$ & 15 & 10 \\
\hline & Post & 0 & 0 & 20 & 5 \\
\hline \multirow[t]{3}{*}{13} & Pre & $<10$ & $<1$ & 12 & 15 \\
\hline & Post & $<10$ & $<1$ & 12 & 15 \\
\hline & Pre & $<10$ & $<1$ & 25 & 15 \\
\hline
\end{tabular}

Table IV Results of bone biopsy before treatment (pre) and after (post) infusion therapy

All the figures are approximate but accurate enough to indicate levels above or below critical values (see text). 
porosis due to reduced formation and active, but normal, resorption. In case 9 the pretreatment biopsy was too small for quantitation although its fragmented nature suggested osteoporosis. After treatment postmortem study showed no osteoid and marked osteoporosis in all the bones examined (iliac crest, a lumbar vertebra, rib, and femur).

\section{RETENTION OF INFUSATE}

Six patients had ${ }^{47} \mathrm{Ca}$ pulse labelling of the infusion on the first day of a treatment course (table V). Two of these patients had normal absorption of an oral ${ }^{47} \mathrm{Ca}$ dose before the infusion (cases 7 and 8 ). These two showed the highest ${ }^{47} \mathrm{Ca}$ urinary excretion and lowest whole body retention. In contrast the lowest urinary excretion and highest whole body retention was seen in the patient with early osteomalacia (case 11).

\begin{tabular}{|c|c|c|c|c|c|c|}
\hline & \multicolumn{6}{|c|}{${ }^{1 C}$ Ca Pulse Labelling of First Infusion } \\
\hline & \multicolumn{6}{|c|}{ Case No. } \\
\hline & 3 & 4 & 7 & 8 & 11 & 13 \\
\hline $\begin{array}{l}\text { Twelve-day retention by } \\
\text { whole body counting (\%) } \\
\text { Percentage of dose in urine } \\
\text { in } 12 \text { days }\end{array}$ & $\begin{array}{l}38 \\
28\end{array}$ & $\begin{array}{l}36 \\
29\end{array}$ & $\begin{array}{l}24 \\
41\end{array}$ & $\begin{array}{l}20 \\
46\end{array}$ & 72 & $\begin{array}{r}47 \\
21\end{array}$ \\
\hline
\end{tabular}

Table V Retention of ${ }^{47} \mathrm{Ca}$ infusate

\section{Discussion}

In all 14 patients with primary biliary cirrhosis calcium infusions induced relief of bone pain. This occurred within three to 12 days of starting the infusions and lasted for two to three months, when a subsequent course of infusions was again effective. There were no serious complications. The absence of side effects was consistent with the small and unsustained increases in plasma calcium concentration.

In spite of regular parenteral vitamin D treatment gastrointestinal calcium absorption, as measured by retention, was subnormal in six patients. This was unaffected by the infusions. These findings are not in agreement with those of Pak et al (1969) who reported an improvement in intestinal calcium absorption after calcium infusion treatment in four of their osteoporotic patients who were responsive to treatment with no significant change in the other two who were unresponsive. A lack of effect on intestinal calcium absorption with calcium infusion treatment could, however, be expected from a consideration of the factors involved in intestinal calcium absorption, the most important factor in which is 1,25-dihydroxycholecalciferol (Wills, 1973). The rate of renal synthesis of this steroid hormone is under feed-back control; the likely determinant would appear to be intracellular calcium concentration (Galante, Colston, Evans, Byfield, Matthews, and MacIntyre, 1973). It was expected that calcium infusions would, through the feed-back control mechanism, tend to reduce the rate of renal synthesis of 1,25-dihydroxycholecalciferol with a consequent decrease rather than increase in intestinal calcium absorption.

Two of the patients had histological evidence of osteomalacia, despite long-term intramuscular vitamin D therapy. In one of these two patients a bone biopsy after treatment showed healing of the osteomalacia. In the 14 patients studied this constitutes the only objective evidence of a beneficial effect of the infusions. Healing of osteomalacia was also seen in a further patient with secondary biliary cirrhosis whose pain was relieved by infusion treatment.

The retention of radiocalcium-labelled infusate, and presumably infused calcium, showed wide variations between patients. One patient with osteomalacia appeared to have an exceptional avidity for infused calcium-retaining $72 \%$ of the infused radioisotope after 12 days. A similar result was found in the patient with secondary biliary cirrhosis and osteomalacia. These high retentions, with corresponding low urinary outputs, resemble the results found in osteomalacia by the calcium infusion test (Nordin and Fraser, 1956; Kehayoglou, Holdsworth, Agnew, Whelton, and Sherlock, 1968). The highest urinary outputs of infused radiocalcium were found in two patients with normal calcium absorption. In two of the other patients there was histological evidence of osteoporosis and in the remainder iliac crest biopsy was normal. In view of the bone pain it is possible that there could have been metabolic bone disease at other sites.

The subjective relief of bone pain was similar to that reported by Pak et al (1969) in six patients with idiopathic osteoporosis. Sekel (1973) also reported the relief of bone pain following a course of calcium infusions in patients with Paget's disease of bone and noted 'striking relief from pain after the third day of infusion and relief has persisted sixteen weeks after the infusion ceased'. In contrast to the findings of Pak et al (1969), after the course of calcium infusions we found no changes in calcium retention or in bone biopsies, with one exception (case 10). Their studies, however, were performed on patients with idiopathic osteoporosis.

The mechanism of the effectiveness of intravenous calcium infusion therapy in the relief of bone pain in the group of patients with primary biliary cirrhosis 
studied here is not clear. Pak et al (1969) suggested that hypercalcaemia induced by an intravenous infusion of calcium might suppress endogenous parathyroid hormone secretion and stimulate calcitonin secretion which would therefore lead to the induction of a positive calcium balance and the extent of this effect would depend on the dose of calcium. This view is consistent with the more rapid onset of relief from bone pain in those patients who received the high dose infusion. It is, however, difficult to understand why the infusion of only a relatively small amount of calcium, as given in the low dose therapy, should produce a dramatic clinical response. In view of the entirely subjective nature of the response obtained it could be argued that the effect was a placebo reaction. Despite these arguments it is concluded that this form of therapy is of value in the relief of the bone pain which occurs in patients with primary biliary cirrhosis despite vitamin D therapy, and possibly of that associated with hepatic osteodystrophy in other hepatobiliary disorders.

\section{References}

Agnew, J. E., Kehayoglou, A. K., and Holdsworth, C. D. (1969).
Comparison of three isotopic methods for the study of calcium absorption. Gut, 10, 590-597.

Atkinson, M., Nordin, B. E. C., and Sherlock, S. (1956). Malabsorption and bone disease in prolonged obstructive jaundice. Quart. J. Med., 25, 299-312.

Byers, P. (1974). The diagnostic value of bone biopsies. In Metabolic Bone Disease, edited by L. V. Avioli. Academic Press, New York and London. (In press).

Drury, R. A. B., and Wallington, E. A. (1967). Carleton's Histological Technique, 4th ed., pp. 147-149. Oxford University Press, New York and Toronto.

Galante, L., Colston, K. W., Evans, I. M. A., Byfield, P. G. H., Matthews, E. W., and MacIntyre, I. (1973). The regulation of vitamin D metabolism. Nature (Lond.), 244, 438-440.

Kehayoglou, A. K., Holdsworth, C. D., Agnew, J. E., Whelton, M. J., and Sherlock, S. (1968). Bone disease and calcium absorption in primary biliary cirrhosis with special reference to vitamin D therapy. Lancet, 1, 715-719.

Lichtwitz, A., Cachin, M., Hioco, D., Tutin, M., and de Sèze, S. (1959), Le syndrome phosphocalcique des cirrhoses. Sem. Hop. Paris. 35, 2399-2409.

Nordin, B. E. C., and Fraser, R. (1956). A calcium-infusion test. I. Urinary excretion data for recognition of osteomalacia. Lancet, 1, 823-826.

Pak, C. Y. C., Zisman, E., Evens, R., Jowsey, J., Delea, C. S., and Bartter, F. C. (1969). The treatment of osteoporosis with calcium infusions. Amer. J. Med., 47, 7-16.

Sekel, R. (1973). Calcium infusion in painful Paget's disease of bone. Lancet, 1, 372-373.

Sherlock, S. (1974). Diseases of the Liver and Biliary Tract, 4th ed. Blackwells, London.

Sherlock, S., and Scheuer, P. J. (1973). The presentation and diagnosis of 100 patients with primary biliary cirrhosis. New Engl. J. Med., 289, 674-678.

Wills, M. R. (1973). Intestinal absorption of calcium. Lancet, 1, 820-823. 